\title{
Editorial
}

\section{The joys and sorrows of logos and slogans in place branding}

Place Branding and Public Diplomacy (2013) 9, 217-222. doi:10.1057/pb.2013.28

First of all, full disclosure: on the subject of logos and slogans for places, I am like the former house burglar turned security consultant. I spent a decade creating and selling logos and slogans to places until, rather recently, I saw the light and changed my approach to place branding. Now, instead, I expend my energies and creative powers devising dramatic actions and policy recommendations for places, which, if implemented, can transform (or at least adjust) places' images and reputations. Of course, like the supposedly reformed burglar, I still dabble in the dark arts: for one, great graphic design excites me and copywriting I am good at; but also, as I'll explain here, I do believe these much-maligned tools have a legitimate role in place branding, albeit a limited and delimited one.

\section{WHY PLACES HAVE LOGOS AND SLOGANS}

In issue 9.2 of this journal, in this very space, Robert Govers wrote that: 'As places already have (more often than not meaningful) names and landmarks, the amount of time and investment generally spent on designing logos and slogans as opposed to actual reputation management for places, seems to be a waste'. Although it seems impossible to disagree with that statement, Govers' assertion prompts a follow-up question: if logos and slogans are so useless, relatively speaking, why are the marketing managers of places so obsessed with them?
As a practitioner with experience in the field, I believe there are several answers:

(1) Letterhead needs something in the upper righthand corner. Places, or place-promoting organizations, like any corporate entity, require a certain amount of graphic design to function normally; this can't be escaped no matter how fundamentally correct the 'logos aren't very powerful levers in the grand scheme of things' view is.

(2) Ease of purchase. Graphic design, headlines and other types of identification and communications can be bought, by a single department head, out of this year's budget. By contrast, a recognizable skyline, a world-famous ancient monument or an 8 per cent GDP growth rate - all of which are more attractive than the most beautiful logo or sonorous strapline - are far harder to come by.

(3) Prestige and pleasure. Like shopping for fancy clothes, procuring graphic design or other creative work makes the buyer feel that his or her place and organization are important. Moreover, like shopping, it's a lot of fun having talented people with taste flattering you with their attentions, trying to please you by bringing you things to look at, ponder and choose from (the way a design process typically transpires).

(4) Peer pressure and one-upsmanship. You don't want to be the only place to show up at a big international conference without a polished brand identity; how 
would that look?! When 'everybody's doing it', bad habits prove especially hardy, and the desire to outcompete one's rivals - to stand out favourably and slickly from the crowd, but not by too much - induces a cycle of bigger budgets and ever more mannered and less distinguished place brand identities.

Nonetheless, even if logos and slogans pale in effectiveness compared with other identity management tools, if a place is going to have them - and it probably is - they might as well be halfway decent; there's no argument there.

\section{SUCCESS FACTORS IN LOGOS AND VISUAL SYSTEMS}

Arguably the best visual system for a place in use right now is the one in Peru. I say visual system, but really it's just a logo, or more accurately a wordmark - the branding jargon for a letter forms done in a certain way. However, it feels like a system because it's used in so many contexts. When you visit Peru, you see it everywhere, in both official and unauthorized uses, from the tailfins of airplanes to bootleg T-shirts, from the national coinage to ice cream shops in Andean mountain towns (Figures 1-5).

Looking at the Peru logo and several others that outpace the (admittedly crowded) field, some success factors for the visual identity of places become apparent.

\section{The identity is discovered rather than concocted}

The Peruvian mark is an unsubtle visual quotation of the 1500-year old monkey's tail drawing in

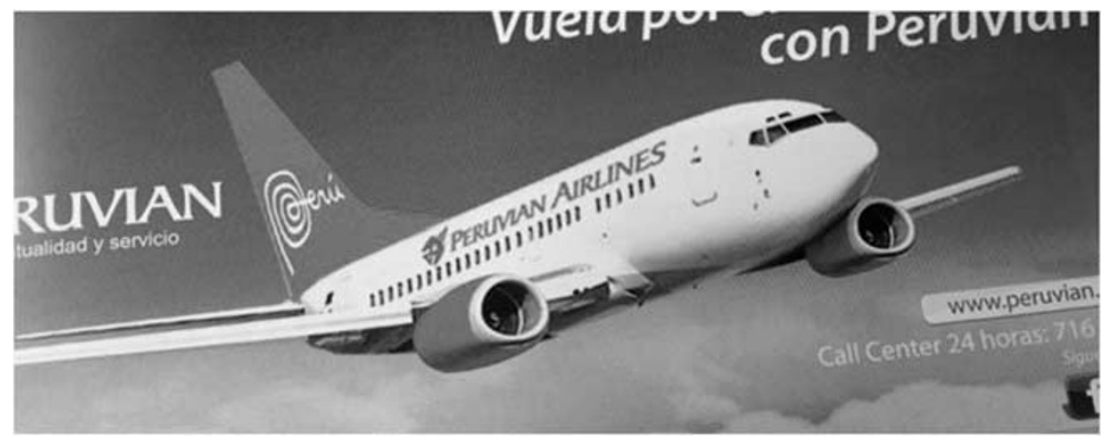

Figure 1: Peru logo on airplane.

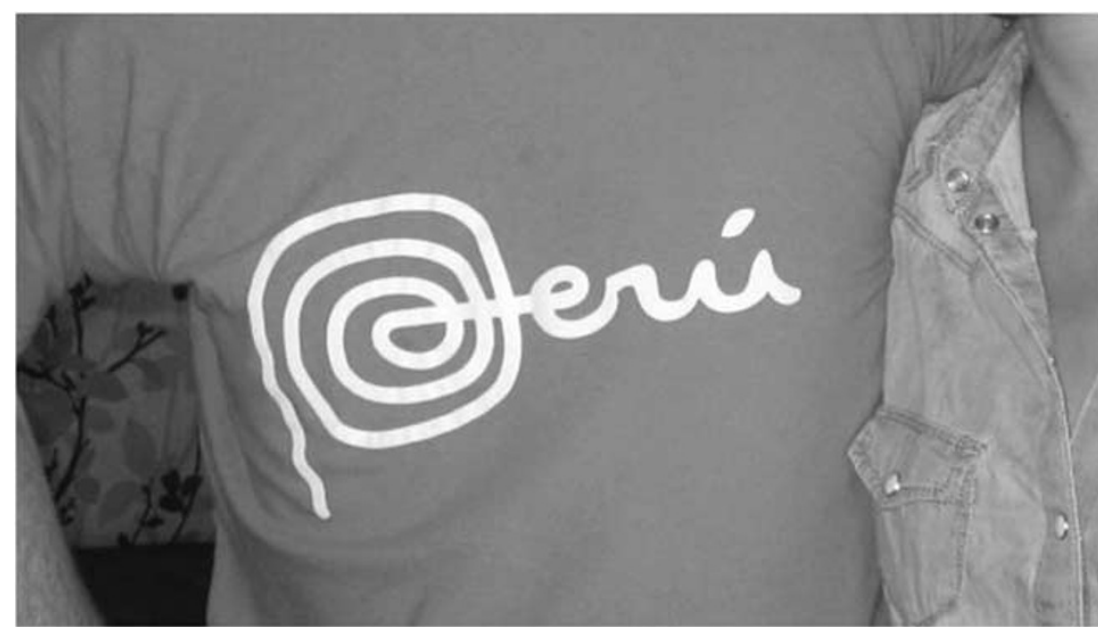

Figure 2: Peru logo on bootleg T-shirt purchased \& worn by the author. 
Nazca, Peru. This is a ploy, sure, but it makes the logo real, tangible, direct and authentic. It's not like some meaningless brushstroke logo intended to convey friendliness because it's soft. Moreover, the spiral is already recognized and associated with Peru, so it transfers existing 'brand equity' to the logo.

\section{Outsiders are involved in the design process}

Although the Peruvian logo is hugely popular with Peruvians, in fact it was designed by the

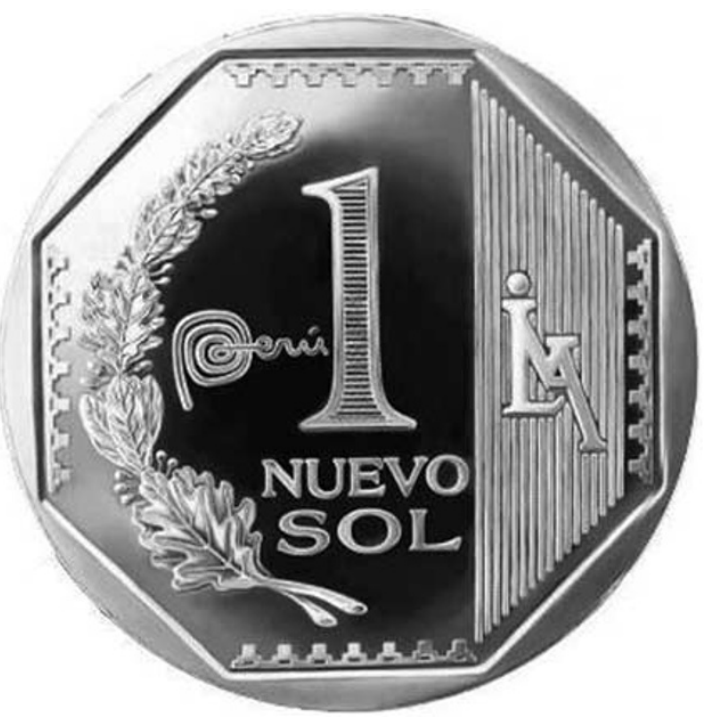

Figure 3: Peru logo on coinage.
Argentinian office of FutureBrand (with plenty of Peruvian collaboration, assuredly). However, the fact is, logos that are entirely homegrown seem to be less successful than ones that take cognizance of the outsider's sense of a place.

\section{The primary mark itself is neither playful nor austere}

Some allowance might be made here for tourism logos, but generally speaking place logos are better off playing it fairly straight. Forced cuteness is to be avoided, as is looking like a bank; somewhere in between, the truth lies. Too many pastel colours, or any use of a heart shape whatsoever, are the kiss of death, as well as an admission of utterly failed imagination.

\section{The identity system is managed intelligently}

The policy of PromPeru, the national promotional organization who are the originators and stewards of the Peruvian logo, is to allow - even to encourage - all but the most outlandish or untoward deployments of the logo by amateurs. In addition, and smartly, in order to encourage the popularity of the mark early on, they licensed it for free to corporations willing to use it on their products (although the idea is to charge a licence fee at some point to help fund the programme). The theory is that maintaining too-tight control over the logo before it has

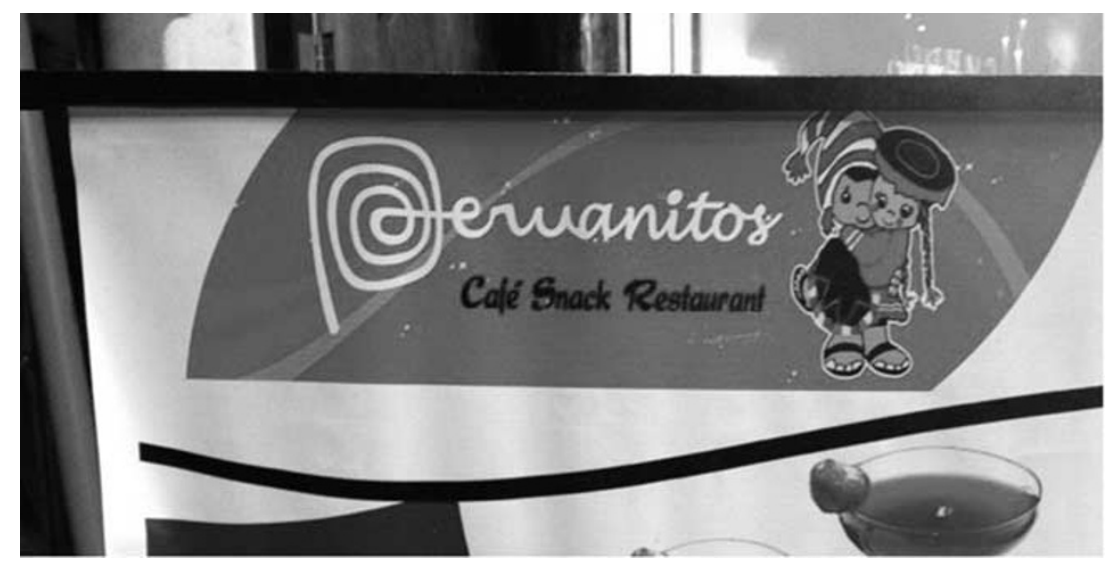

Figure 4: Peru logo unofficially appropriated by a cafe. 


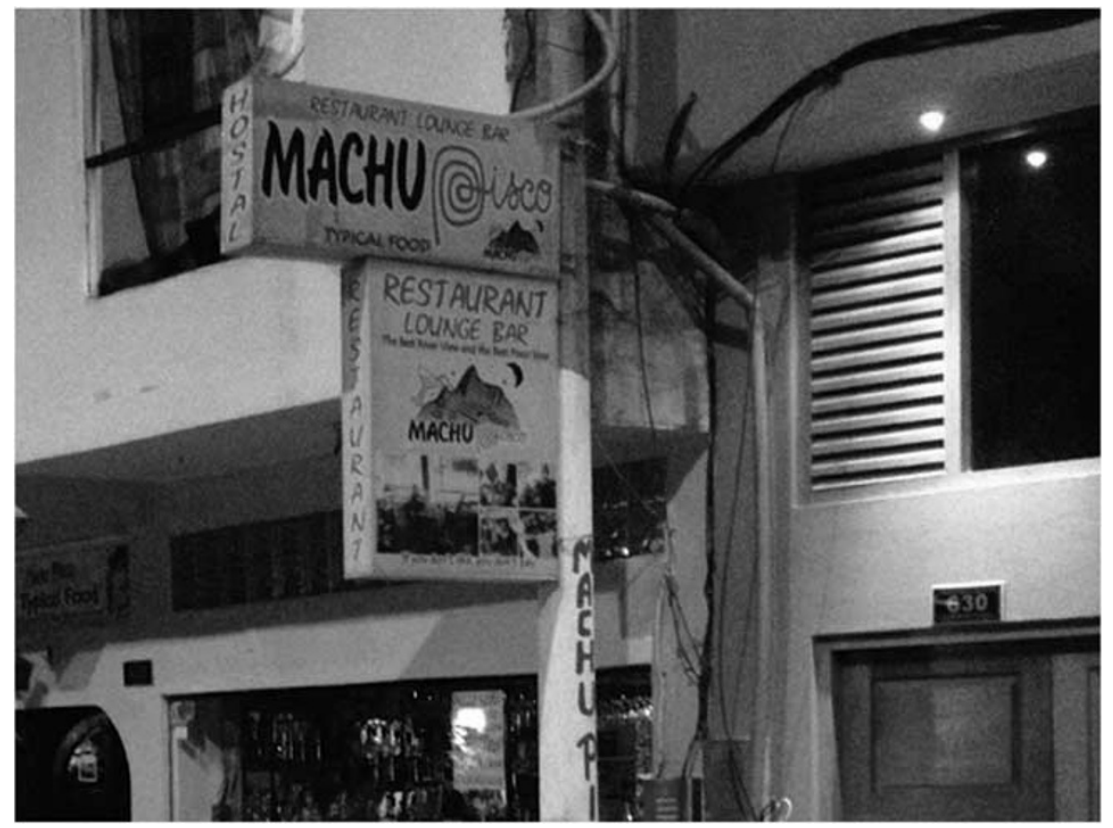

Figure 5: Peru logo affectionately bastardised on a bar in Aguascalientes.

become popular might keep it from becoming popular in the first place.

\section{The logo is the invention of a celebrity}

Spain's famous 'sun' tourism logo was drawn by one of the country's most revered artists, Joan Miro. I humbly submit that had an identical logo been created by an anonymous graphic artist, it would have been replaced several times by now. Whatever its merits as an insignia, the fact that a superstar designed it makes it somewhat sacred and helps ensure its longevity. Another possible example of this effect: 'I heart NY' - originally an initiative of New York State and not New York City (people forget that) - came from the hand and mind of a legend, Milton Glaser of Push Pin Studios; that hasn't mattered for some time, but it may have done so in the early days.

\section{Time happens to pass}

Almost no design is loved from day one. Some thought Miro's Spanish sun looked like a fried egg. If a logo manages to survive a couple of years, people get the chance to grow familiar with it. This familiarity can then morph into a kind of attachment or affection. Momentum is thus attained. Hence, logos that last awhile tend to keep sticking around.

\section{You'd buy the T-shirt}

The ultimate standard of a logo for a place is whether or not people would pay money to have it as a souvenir on items of clothing. Not many successful and long-lived logos fail this test.

\section{SUCCESS FACTORS IN SLOGANS}

For my money, there are two factors involved in most successful slogans: factuality and musicality.

Factuality - Most slogans used by places are surprisingly devoid of interesting facts. The best slogans manage to get an interesting fact across with a certain flair, although doing so is more art than science. Years ago, for Visit London (the marketing department for Europe's largest city), I wrote a few straplines to go interchangeably with the organization's wordmark. The one everyone liked the best, and which was used for a couple of years, was 'Visit London: it rains more in Rome'. (It's a fact; you can look it up; accumulated annual rainfall is higher in Rome). Caveat: many of the greatest 


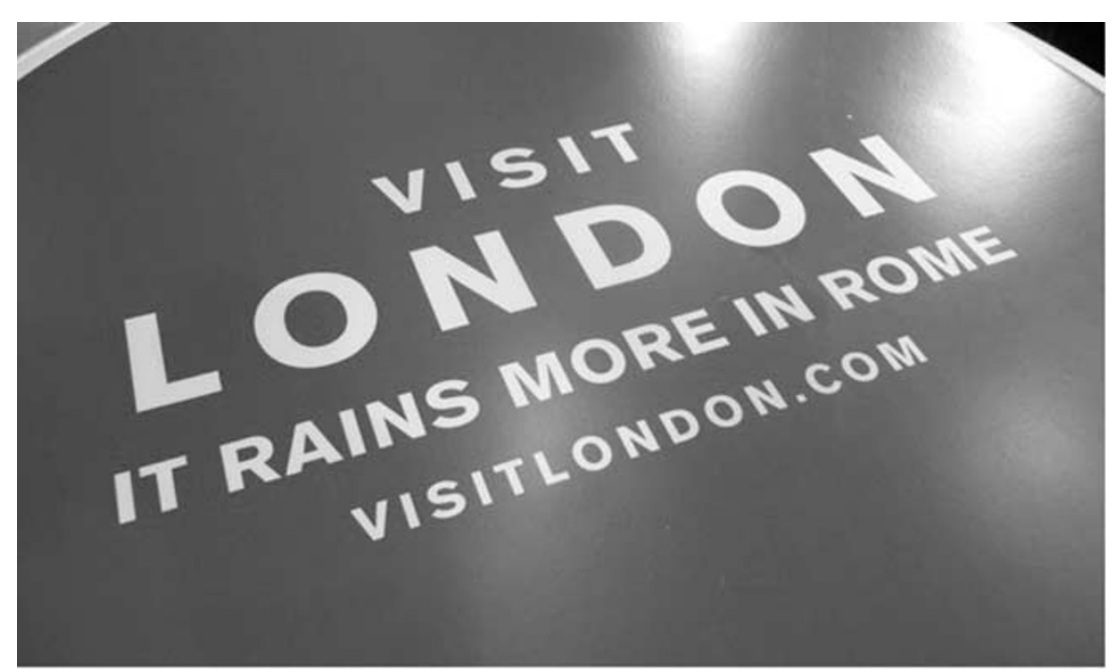

Figure 6: 'Visit London: It rains more in Rome'.

slogans do not follow this rule and contain no facts whatsoever (for example, 'What happens in Vegas stays in Vegas'); but when it doubt, I recommend sticking to a fact-based slogan (Figure 6).

Musicality - Just as people often have a tendency to want to blurt out exactly what's on their mind, so do places seem to want to tell you, in their slogans and straplines, exactly what they want you to know about them, and in the least poetic, least inspiring and most breathlessly florid and nakedly manipulative language possible. The unfortunate result of this widespread practice is a surfeit of dull or weird slogans like: 'Chile: All Ways Surprising', or 'I Feel Slovenia' or, my favourite, 'Panama: It will never leave you'. ('100 per cent pure New Zealand' sounds dumb too, even when you know what a splendid success it's supposedly been).

The missing ingredient, in a word, is musicality quite plainly, the way the words sound. Rhythm. Cadence. Tone. Timbre. Vibrato. Phrasing. When it comes to a slogan, these things matter a lot.

In his book You Are The Message, Roger Ailes gives an anecdote about Mark Twain, which illustrates my point. Twain, trying to get dressed one morning, pulled out three shirts in a row that were short a button:

Twain flew into a rage, swearing like a stevedore. When he was through, he was startled to see his wife standing at the door, fuming in her own way at his intemperance. Carefully, slowly, and without a trace of emotion, she repeated every obscene word just uttered by her husband ... When she was through, she stood impassive and silent, hoping her display would shame Twain. Instead, with a twinkle in his eye, he puffed his cigar and said, 'My dear, you have the words, but you don't have the music'.

There you go: it's what you say and the way that you say it.

\section{COMMISSIONING (AND TRANSCENDING) LOGOS AND SLOGANS}

Imagine a necktie if you are a man, or a handbag if you are a woman. How important is it to one's image to have a great one? Well, to my way of thinking, you definitely don't want to be seen in public with something awful, and if you have a superb one that garners compliments, so much the better. However, to spend tons of time and money picking one out in preparation for job interview or board presentation would demonstrate a tragic loss of perspective about what makes a successful career. As an element of your self-presentation on the day of a pivotal meeting, a fashion accessory won't provide much of a leg up. Against the smoothness and erudition and energy you project, 
Inset box: The gold standards

My favourite place logo is Bermuda's shorts (pictured nearby), and my favourite place slogan is 'Any decent doctor would prescribe Norway'. I had nothing to do with either of them (though I wish I had) and I'm uncertain for how long, respectively, they were in use, or whether or not they are regarded as successful. I like them because they are rooted in authentic, even singular, identity features of the places they represent and then reach out in a human, even humorous, way to an audience of potential customers (for tourism, in this case). Although they both break some of the rules I set for successful logos and slogans, they have panache and pizzazz, which are worth breaking rules to achieve. That said, they meet the ultimate test of a place logo or place slogan: you might actually buy the T-shirt (Figure 7).

it's a triviality. And set in the context of your existing relationships, reputation, character and personality, it's downright insignificant.

So it is with logos and slogans. They're pretty much like neckties and handbags: nicer is almost always better, but anything north of 'distractingly hideous' or 'unbelievably cheap and nasty' should get you by.

Unsurprisingly, the way to handle commissioning logos and slogans is the same way you'd handle the task of acquiring a snazzy and suitable handbag or a necktie: if you trust your own taste, pick it out yourself; if you don't, get the advice of someone who's taste you do trust - and, barring them trying to stick you with something that well and truly 'just isn't you', take their advice with gratitude. You would not appoint a committee to choose your fashion accessories; don't do it for your graphic design or copywriting either. Hire a designer or writer you trust, let them get to know you - test them if you wish, as their understanding of you will be the wellspring of their work on your behalf - and then be predisposed to use their output with little or no alteration.

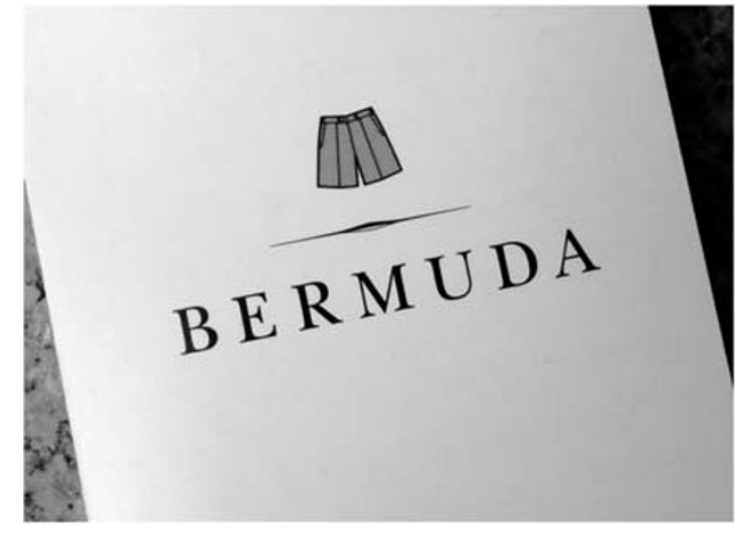

Figure 7: 'Bermuda shorts'.

\section{TRANSCENDING LOGOS AND SLOGANS}

Although I've argued here that logos and slogans are, in fact, reasonable things for a place to possess and use, I must at last address the bigger issue suggested by Govers: that graphic design-oriented place branding programmes are, to a considerable degree, a displacement activity for genuine place reputation management and development. My evolved view is that in an ideal situation, no more than 10 per cent of a place's identity budget would go toward developing logos and slogans and other signifiers, whereas 90 per cent or more of the budget would be used to fund identity-enhancing actions and identity-centric substance, both of which speak louder than words, or logos.

Jeremy Hildreth is co-founder of Thrilling Cities, a place branding agency that produces profile-raising actions, policies, communications and graphic design. 